\title{
Antiobesity and Lipid Lowering Activitiy of Vigna unguiculata (L) Walp. Seed in High Fat Diet Induced Obese Mice
}

\author{
Md. Saddam Hussain, Mohammad Salim Hossain* and Md. Mamun Or Rashid
}

\author{
Department of Pharmacy, Noakhali Science and Technology University, Noakhali-3814, Bangladesh
}

\begin{abstract}
Seed of Vigna unguiculata is commonly used as culinary in Bangladesh and many parts of the world. Besides this, seed of $V$. unguiculata possesses some medicinal values like being an antioxidant etc. In this study, seeds of $V$. unguiculata were used to determine the link between its total phenolic content and lipid lowering activity. Phytochemicals presents in the seeds were evaluated. Total phenolic content (TPC) was determined by using folin-ciocalteu method. High fat diet induced obese mice were used for anti-obesity and antihyperlipidemic test. Body weight gain, total cholesterol and triglyceride levels were analyzed. Preliminary phytochemical screening showed that amino acid, phenol, alkaloid and terpenes were very strongly present in cowpea seed, while carbohydrate, cardiac glycoside, was moderately present. The $V$. unguiculata seeds showed significant total phenolic content with a value of $119.716 \mathrm{mg}$ of $\mathrm{GAE} / \mathrm{gm}$ equivalent. Cowpea seeds, with a dose of $400 \mathrm{mg} / \mathrm{kg}$ body-weight, showed significant reduction in body weight gain when treated with fat diet compared with normal diet. Cowpea seeds are also capable of lowering the serum cholesterol $(p<0.01)$ and serum triglyceride level $(p<0.01)$ more significantly in high fat diet induced obesity. $V$. unguiculata seeds have a significantly high total phenolic content while the other phytochemicals are moderately present in them. It has anti-obesity activity that can interfere with serum cholesterol and triglyceride metabolism. So, it seems like a healthy diet for the management of obesity and other heart related disease.
\end{abstract}

Keywords: Antihyperlipidemia, Vigna unguiculata(Cowpea), Total phenolic content, Cholesterol, Triglyceride.

(This abstract has been presented on 13th World Congress on Pharmacology and Toxicology, Mercure Albert Park, Melbourne, Australia) [1].

\section{INTRODUCTION}

Obesity and overweight are a major concern in this current world. Attenuated energy expenditure triggers the accumulation of abnormal or excess fat in the body [2]. In addition to excess energy intake, over activity of pancreatic lipase enzyme plays a vital role in the pathogenesis of obesity [3]. Furthermore, obesity has been proved to be linked with different life style diseases like atherosclerosis, [4] diabetes, [5] and hypertension [6] etc. Right now, orlistat, a pancreatic lipase inhibitor [7] and Sibutramine, an appetite suppressant [8] are available in the market for management of obesity. Because of having different side effects [9] of these two drugs including increased blood pressure, dry mouth, constipation and insomnia, the scientists are trying to develop innovative nutritional agents for the management of obesity and overweight.

Human beings have started to use the plants successfully to treat the illnesses from the ancient period of life and the discovery of new molecules from plant sources has renewed the popularity of herbal medicine. Vigna unguiculata L. Walp, commonly known

*Address correspondence to this author at the Department of Pharmacy, Noakhali Science and Technology University, Noakhali-3814, Bangladesh; Tel: +88017711200410; E-mail: pharmasalim@yahoo.com

ISSN: 2223-3806 / E-ISSN: 1927-5951/19 as cowpea, is a legume which is widely cultivated all over the world and their seeds are used as human food as a cheap source of high-quality proteins along with different types of phytonutrients like vitamin, minerals and insoluble dietary fibres. Beside this, V. unguiculata has been studied for different medical benefits. Cowpea seeds are considered as nematocidal and antifungal [10]. Powder of seeds when mixed with oil is used in treating stubborn boils [11]. Several studies have demonstrated that the compound having antioxidant activity is considered to be a good candidate for the management of obesity [12]. Cowpeas have been documented because of their antioxidant activities [13] but nothing is known for its effect on obesity. Thus, after taking all these things in consideration, we aimed to study the anti-obese potentiality of cowpea seeds.

\section{METHODS}

\subsection{Collection of Plant}

For this present investigation $V$. unguiculata Linn (seeds) were collected from Noakhali, Bangladesh on April, 2015. After collection, the seeds were thoroughly washed with water and then dried under sunlight. The plant was identified by an expert of Bangladesh National Herbarium, Mirpur, Dhaka, Bangladesh. (Accession number: 37752).

๑) 2019 SET Publisher 


\subsection{Preparation of Aqueous Suspension of $V$. unguiculata Seeds for Anti-Obese Activity}

The dried seeds $(500 \mathrm{gm})$ were powdered and the required amount of powder, at the dose of $400 \mathrm{mg} / \mathrm{kg}$ body weight, was calculated and weighed accurately. Afterwards, it was suspended in the water, containing few drops of Tween 80 , to make a suspension of $10 \mathrm{mg} / \mathrm{ml}$. One (1) $\mathrm{ml}$ of this suspension was administered to each mouse, where applicable.

\subsection{Preparation of Methalonic Extract of $V$. unguiculata Seeds}

Adequate amount of powdered seeds was soaked in methanol with occasional shaking for 15 days. Solution was then filtered using a filter cloth and the Whatman ${ }^{\circledR}$ filter paper No. 1. The resulting filtrates were then evaporated in a rotary evaporator below $40^{\circ} \mathrm{C}$ to dryness and thus a concentrated semisolid mass of the extract was obtained.

\subsection{Experimental Animals}

Swiss albino mice, used for this study were collected from Jahangir Nagar University, Savar, Dhaka, Bangladesh and were kept in polypropylene cages where they were exposed to alternate cycles of $12 \mathrm{hr}$ dark and $12 \mathrm{hr}$ light at a temperature of $25 \pm 2^{0} \mathrm{C}$ and relative humidity of $55 \pm 10 \%$. Mice were fed with standard laboratory pellet diet and water at libitum, and were allowed to acclimatize for 7 days to the laboratory conditions before the experiment. Mice were given adequate human care throughout the experimental period.

\subsection{Study Design}

Twenty experimental healthy mice were randomly selected and divided into four groups with five mice in each group.

Group-1: Control group, where all of the mice were fed with normal food.

Group-2: Mice fed with normal diet along with aqueous extract at $400 \mathrm{mg} / \mathrm{kg}$ body weight.

Group-3: Obese group, mice fed with high fat diet; $20 \%$ (w/w) cow fat along with normal diet (HFD group).

Group-4: Mice fed with high fat diet with aqueous extract at $400 \mathrm{mg} / \mathrm{kg}$ body weight.

All groups of mice were treated daily with their respective food and water for a period of 11 days and each mouse was weighed on alternate days. At the end of the experimental study, they were anaesthetized before being killed by decapitation and their blood was collected for further analysis.

\subsection{Determination of Total Phenolic Content}

The total phenolic content of the $V$. unguiculata seeds extract was determined by using Folin-Ciocalteu reagent following a slightly modified method of Ainsworth [14]. Gallic acid was used as a reference standard for plotting the calibration curve. A volume of $0.5 \mathrm{~mL}$ of the plant extract $(100 \mu \mathrm{g} / \mathrm{mL})$ was mixed with $2 \mathrm{~mL}$ of the Folin-Ciocalteu reagent (diluted 1:10 with de-ionized water) and were neutralized with $4 \mathrm{~mL}$ of sodium carbonate solution $(7.5 \%, \mathrm{w} / \mathrm{v})$. The reaction mixture was incubated at room temperature for $30 \mathrm{~min}$ with intermittent shaking for colour development. The absorbance of the resulting blue colour was measured at $765 \mathrm{~nm}$ using double beam UV-VIS spectrophotometer (UV Analyst-CT 8200). The total phenolic contents were determined from the linear equation of a standard curve prepared with Gallic acid. The content of total phenolic compounds was expressed as mg/g Gallic Acid Equivalent (GAE) of the dry extract.

\subsection{Determination of Serum Cholesterol}

Serum cholesterol level were calculated by enzymatic end point (CHOD-PAP) method [15] by using a double beam spectrophotometer (Shimadzu, Japan). In detail, the cholesterol concentration was determined through oxidation of enzymatic hydrolysis. Due to the chemical changes occuring in the presence of phenol and peroxidase, hydrogen peroxide is produced which then reacts with 4-aminophenazene and produces colorquinoneimine as an indicator. During this study, three washed test tube were taken at first and labelled as 'Blank', 'Standard' and 'Serum sample' respectively. Then, $10 \mu \mathrm{l}$ of serum sample was taken to a test tube labelled 'sample serum' with the help of micropipette. After that $10 \mathrm{ml}$ of standard Cholesterol sample was taken into the 'standard' labelled test tube. After that $1 \mathrm{ml}$ of enzyme reagent was taken into each test tube respectively and kept for incubation at $37^{\circ} \mathrm{C}$ for 20 minutes, in dark place. The absorption of the solution was measured at $510 \mathrm{~nm}$ against blank. Then absorbance value was put in the cholesterol measuring equation against standard sample and then the cholesterol level was determined. Cholesterol concentration $=\{O D$ of sample $/ O D$ of standard $\} \times 200(\mathrm{mg} / \mathrm{dl})=\{O D$ of sample $/ O D$ of standard $\} \times 5.17(\mathrm{mmol} / \mathrm{l})$. 


\subsection{Determination of Serum Triglyceride}

Serum triglyceride was estimated by enzymatic colorimetric GPO-PAP method [16] by using a double beam spectrophotometer (Shimadzu, Japan). In detail, three washed test tube were taken at first and labelled as 'Blank', 'Standard' and 'Serum sample' respectively. $10 \mathrm{ml}$ of serum sample was taken to a test tube labelled 'sample serum' with the help of micropipette. Then $10 \mu \mathrm{l}$ of standard triglyceride sample was taken into the 'standard' labelled test tube. After that $1 \mathrm{ml}$ of enzyme reagent were taken into each test tube respectively and kept for incubation at $37^{\circ} \mathrm{C}$ for 20 minutes in dark place. The absorption of the solution was measured at 530nm against blank. Then the absorbance value was put in the triglyceride measuring equation against standard sample and the cholesterol level was determined.

Triglyceride concentration $=\{O D$ of sample $/ O D$ of standard $\} \times 200(\mathrm{mg} / \mathrm{dl})=\{O D$ of sample $/ O D$ of standard $\} \times 5.17(\mathrm{mmol} / \mathrm{l})$

\subsection{Statistical Analysis}

All the results were expressed as mean \pm SEM. Pvalue and were calculated by one-way ANOVA using SPSS software, version 22.0 (IBM Corporation, New York, NY, U.S.A.). Where $P \leq 0.05$ was considered as statistically significant.

\section{RESULTS}

\subsection{Phytochemical Analysis of Methanolic Extract of $V$. unguiculata Seed}

Results of phytochemical screening presented in Table 1 revealed that the seeds of $V$. unguiculata possessed high amount of phenol, terpenes and protein followed by alkaloids and carbohydrates (Table 1). Seeds extract were subjected for the determination of total phenolic content and the results was obtained as $119.716 \pm 5.40 \mathrm{mg}$ of GAE (Gallic acid equivalent)/gm dry extract.

\subsection{Effect of $V$. unguiculata Seed on Body Weight}

Animals were grouped randomly and with their average body weight being without considerable differences among the groups at the beginning of the study. Mice fed on normal diet maintained their body weights without fluctuation. Weight of mice of group-3, fed on high fat, started to increase considerably after day 5 and continued till the end of the experiment. Whereas, when the plant's aqueous extracts were
Table 1: Phytochemical Groups Present in $V$. unguiculata Seed

\begin{tabular}{|c|c|c|}
\hline \multirow{2}{*}{ Phytochemicals } & Test & Observation \\
\hline \hline \multirow{2}{*}{ Alkaloid } & Hager's test & ++ \\
\cline { 2 - 3 } & Meyars test & ++ \\
\hline \multirow{2}{*}{ Phenol } & Ferric chloride test & +++ \\
\hline \multirow{2}{*}{ Saponines } & Molisch's Test & + \\
\cline { 2 - 3 } & Benedict's Test & + \\
\cline { 2 - 3 } & Froth test & - \\
\hline Tannin & Foam test & + \\
\hline Flavonoid & Gelatin test & + \\
\hline Protein & Xanthoproteic Test & +++ \\
\cline { 2 - 3 } & Ninhydrin Test & +++ \\
\hline Terpenes & Copper acetate test & +++ \\
\hline
\end{tabular}

Here, +++ very strongly present, ++ strongly present, + weakly present and absent.

administered, regardless of normal diet or high fat, they caused a significant reduction of body weight. The reduction was more prominent in group-4, where the mice were fed with high fat diet with aqueous extract. Mice in group-4, showed a continuous reduction in body weight after the day 6 (Figure 1). There were no remarkable differences in food intake behaviour among the groups.

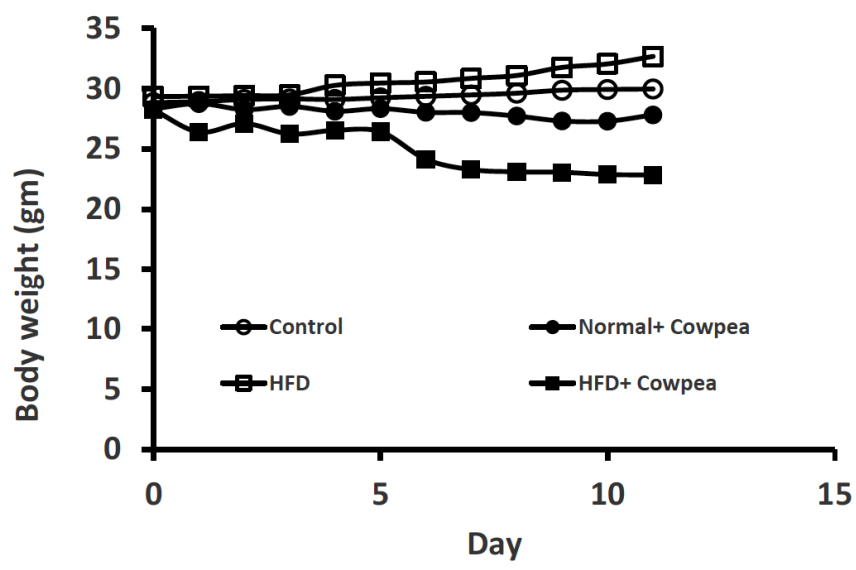

Figure 1: Weight gain by different group of swiss albino mice.

\subsection{Effect of V. unguiculata Seed on Serum Cholesterol}

As predicted, serum cholesterol level was significantly increased in the mice kept on high fat diet compared with normally fed mice. Although, aqueous suspensions were not effective in reducing the cholesterol level in normal fed mice but interestingly, they were able to reverse the effect of high fat induced 


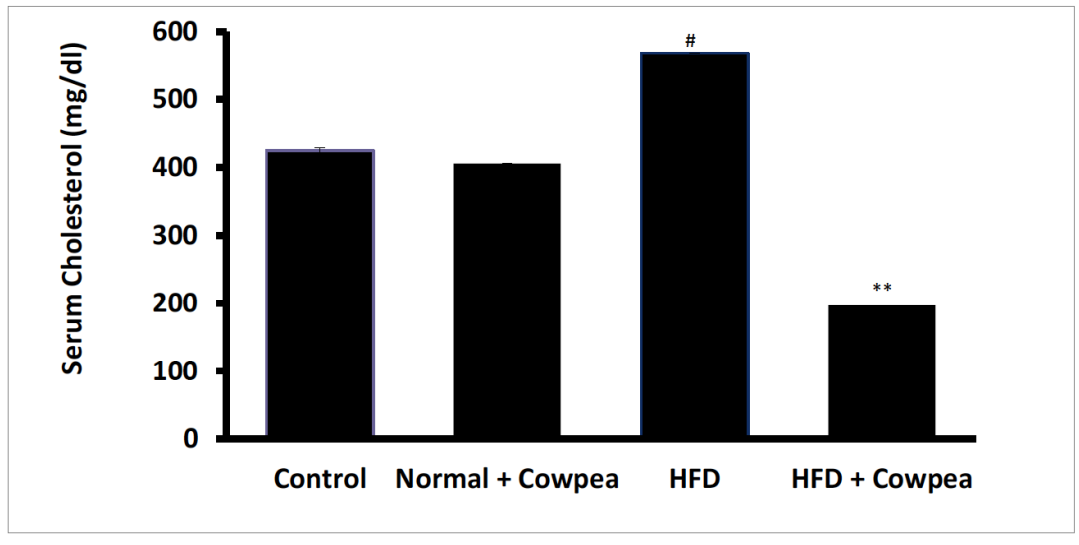

\# $\mathrm{p}<0.05$, versus control, ** $\mathrm{p}<0.01$, versus HFD

$\# p<0.05$, versus control, ${ }^{* *} p<0.01$, versus HFD

Figure 2: Serum cholesterol level in different groups of mice.

hypercholesterolemia significantly $(p<0.01)$ (Figure 2$)$. Cowpea seeds reduced the cholesterol level by around $60 \%$ in HFD group.

\subsection{Effect of $V$. unguiculata Seed on Serum Triglyceride}

Supporting the notion of fat induced obesity, hypertriglyceridemia was observed in mice of HFD group when compared with normal fed diet. Seeds of $V$. unguiculata showed the triglyceride lowering effect in normal fed mice insignificantly but significant $(p<$ 0.01 ) reduction was documented in HFD induced hypertriglyceridemia (Figure 3). Cowpea contributed about $50 \%$ triglyceride reduction in HFD group but in the case of mice with normal diet, it was only $10 \%$.

\section{DISCUSSION}

As like other legumes, V. unguiculata seeds are generally used as food and culinary in Bangladesh and many other parts of the world. Several health-related beneficial effects of this plant have been studied. Here we aimed to explore the lipid lowering activity of this legume. Dose of the extract applied in this study did not cause the death of any experimental mice.

Prevalence of obesity is becoming high in the world and considered as a major risk factor for the development of other health problems [17]. Human studies have been reported which showed that increased fat intake causes the weight gain and develops the obesity with other metabolic complications. Mimicking this episode, high fat died induced obese animal models have been commonly used to study the obesity related changes [18]. In this current study, we also observed significant increased body weight of the mice fed with high fat as compared to those on a normal diet. The treatment with cowpea along with a normal diet or HFD, reduced the body weight. Although cowpea causes reduction in the body

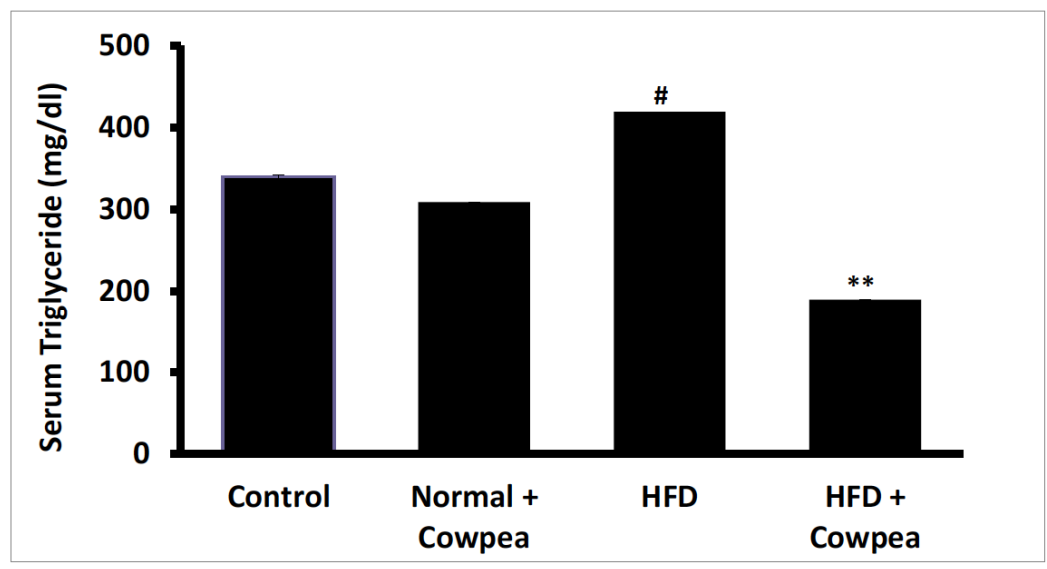

$\# p<0.05$, versus control, ** $p<0.01$, versus HFD

$\# p<0.05$, versus control, ${ }^{* *} p<0.01$, versus HFD

Figure 3: Serum triglyceride level in different groups of mice. 
weight regardless of diet, but cowpea is more prominent to inhibit the weight gain in HFD induced obesity. Cowpea causes about $19 \%$ of weight loss of the mice fed with HFD. During our experiment period, we did not observe any changes in the rate of food intake among the animals, thus this prevention of weight gain might be independent of inhibition of food intake by the treated mice.

Furthermore, hypertriglyceridemia and hypercholesteremia, is being linked with development of obesity and obesity related complications. In this current study, we observed considerable elevated level of triglyceride and cholesterol in the mice fed with HFD compared with normal diet group, but as predicted, treatment with cowpea extract was capable to reduce triglyceride and cholesterol level significantly. Cowpea seeds were effective in reducing cholesterol level to about $60 \%$ and triglyceride level to about $50 \%$ in HFD mice but these values were nearly insignificant in case of normal diet. This result suggests that cowpea may play a role in inhibiting the lipid absorption. This reversing effect of the cowpea confirms its ability to attenuate the obesity and lipid lowering activity. This result motivates us to use this extract for the management of obesity related cardiac complications. Because, it has already been established that drugs having the cholesterol lowering activity are frequently used in the treatment of obesity related cardiac complication [19]. Although it is ambiguous that how this extract reduces obesity and hyperlipidaemia, but some researchers studied that natural products or their derivatives like Orlistat, an anti-obese drug, act by inhibiting the pancreatic lipase to decrease the lipid absorption from gut [20]. Besides this, polyphenols present in plant is an important candidate to inhibit pancreatic lipase [21, 22]. Phytochemical screening (Table 1) of this plant shows that, among other phytochemicals, cowpea seeds possess a high content of polyphenols. The polyphenols may be accounted for the lowering of the lipids in HFD mice by inhibiting the action of pancreatic lipase. Moreover, polyphenols are accounted for the apoptosis of adipocytes [23] and the arrest of cell cycle in $\mathrm{G} 1$ phase to inhibit differentiation of 3T3-L1 adipocytes [24]. Along with polyphenol, alkaloid's present in the plants have also been studied for their anti-obese effect by regulating the lipid metabolism and activating AMP-activated protein kinase [25]. Thus, it could not be excluded that alkaloids present in cowpea seed, along with phenols, might interfere with the lipid metabolic pathway as a result of their anti-obese effects.
Furthermore, in the last few years, obesity is considered as an inflammatory disorder [26, 27] and oxidative stress in a key inducer for obesity mediated inflammation [28]. A diet with high antioxidant capacity has been documented for reversing the central adiposity, metabolic and oxidative stress [29, 30]. Cowpeas have been documented for antioxidant activity [13] and this antioxidant capacity might also be responsible for the management of obesity and oxidative stress in obesity.

\section{CONCLUSION}

Although our present study does not represent the total lipid lowering profile of $V$. unguiculata; but by considering the cholesterol, triglyceride, and body weight lowering index, our data revealed that seeds of cowpea contributed greatly to regulate the pathogenesis of obesity and lipid related metabolism pathway with a possibility of developing anti-obese and lipid lowering drug from $V$. unguiculata (seed). Further studies are warranted for finding out this bioactive metabolite.

\section{COMPETING INTEREST}

The authors declare no conflict of interest

\section{ACKNOWLEDGEMENT}

The authors are thankful to all the teachers and staffs of the Department of Pharmacy, Noakhali Science and Technology University for their support and co-operation.

\section{AVAILABILITY OF DATA AND MATERIALS}

Data and materials are available in the department of pharmacy, Noakhali Science and Technology University.

\section{FUNDING INFORMATION}

None.

\section{REFERENCES}

[1] Hussain MS, Hossain MS, Rashid MMO. Antiobesity and lipid lowering activitiy of Vigna unguiculata (L) Walp. seed in high fat diet induced obese mice. 113th World Congress on Pharmacology and Toxicology, Mercure Albert Park, Melbourne, Australia, November 14-152018.

[2] Spiegelman BM, Flier JS. Obesity and the regulation of energy balance. Cell 2001; 104(4): 531-543. https://doi.org/10.1016/S0092-8674(01)00240-9

[3] Chandrasekaran C, Vijayalakshmi M, Prakash K, Bansal V, Meenakshi J, Amit A. Review Article: herbal approach for 
obesity management. American Journal of Plant Sciences 2012; 3(7): 1003-1014.

https://doi.org/10.4236/ajps.2012.327119

[4] Azimi A, Charlot MG, Torp-Pedersen C. Gislason GH, Køber $\mathrm{L}$, Jensen LO, Thayssen P, Ravikilde J, Tilsted HH, Lassen JF, Thuesen L. Moderate overweight is beneficial and severe obesity detrimental for patients with documented atherosclerotic heart disease. Heart 2013; 99(9): 655-660. https://doi.org/10.1136/heartjnl-2012-303066

[5] Nath D, Heemels MT, Anson L. Obesity and diabetes. Nature 2006; 444(7121): 839. https://doi.org/10.1038/444839a

[6] Dorresteijn JAN, Visseren FLJ, Spiering W: Mecha- nisms linking obesity to hypertension. Obesity Reviews 2012; 13(1): 17-26. https://doi.org/10.1111/j.1467-789X.2011.00914.x

[7] Drew BS, Dixon AF, Dixon JB: Obesity management: update on orlistat. Vascular Health Risk Management 2007; 3: 817821.

[8] Tziomalos K, Krassas GE, Tzotzas T. The use of sibutramine in the management of obesity and related disorders: an update. Vascular Health Risk Management 2009; 5: 441-452. https://doi.org/10.2147/VHRM.S4027

[9] De Simone G, D'Addeo G. Sibutramine: balancing weight loss benefit and possible cardiovascular risk. Nutrition, Metabolism \& Cardiovascular Diseases 2008; 18: 337-341. https://doi.org/10.1016/j.numecd.2008.03.008

[10] Zia-ul-Haq M, lqbal S, Ahmad S, Bhanger MI, Amarowicz R. Antifungal and nematicidal activity of selected legumes of Pakistan. Pakistan Journal of Botany 2010; 42: 1327-1331.

[11] Duke JA. Introduction to food legumes. In: Insect Pests of Tropical Food Legumes, (Ed.): S.R. Singh. John Wiley and Sons, Chichester, UK 1990.

[12] Mashmoul M, Azlan A, Khaza'ai H, Yusof BNM, Noor SM. Saffron: A Natural Potent Antioxidant as a Promising AntiObesity Drug. Antioxidants 2013; 2: 293-308. https://doi.org/10.3390/antiox2040293

[13] Zia-Ul-Haq M, Ahmad S, Amarowicz $R$, De Feo V. Antioxidant Activity of the Extracts of Some Cowpea (Vigna unguiculata (L) Walp.) Cultivars Commonly Consumed in Pakistan. Molecules 2013; 18: 2005-2017. https://doi.org/10.3390/molecules 18022005

[14] Ainsworth EA, Gillespie KM. Estimation of total phenolic content and other oxidation substrates in plant tissues using Folin- Ciocalteu reagent. Nature Protocols 2007; 2(4): 875877.

https://doi.org/10.1038/nprot.2007.102

[15] Allain CC, Poon LS, Chan CS, Richmond W, Fu PC. Enzymatic determination of total serum cholesterol. Clinical Chemistry $1974 ; 20(4): 470-5$.

[16] Bucolo G, David H. Quantitative determination of serum triglycerides by the use of enzymes. Clinical Chemistry 1973; 19(5): 476-82.

[17] Wang Y, Lobstein T. Worldwide trends in childhood overweight and obesity. International Journal of Pediatric Obesity 2006; 1(1): 11-25. https://doi.org/10.1080/17477160600586747

[18] Neyrinck AM, Bindels LB, De Backer F, Pachikian BD, Cani PD, Delzenne NM. Dietary supplementation with chitosan derived from mushrooms changes adipocytokine profile in diet-induced obese mice, a phenomenon linked to its lipidlowering action. International Immunopharmacology 2009; 9(6): 767-773.

https://doi.org/10.1016/j.intimp.2009.02.015

[19] Anon. Provastatin, simvastatin and lovastatin for lowering serum cholesterol concentration. The Medical Letter on Drugs and Therapeutics 1992; 34: 57-8.

[20] Ballinger A, Peikin SR. Orlistat: its current status as an antiobesity drug. European Journal of Pharmacology 2002; 440: 109-17.

https://doi.org/10.1016/S0014-2999(02)01422-X

[21] Han LK, Takaku T, Li J, Kimura Y, Okuda H. Anti-obesity action of oolong tea. International Journal of Obesity and Related Metabolic Disorders 1999; 23: 98-105. https://doi.org/10.1038/sj.ijo.0800766

[22] Lin JK, Lin-Shiau SY. Mechanisms of hypolipidemic and antiobesity effects of tea and tea polyphenols. Molecular Nutrition \& Food Research 2006; 50: 211-7. https://doi.org/10.1002/mnfr.200500138

[23] Hwang JT, Park IJ, Shin JI, Lee YK, Lee SK, Baik HW, Ha J, Park OJ. Genistein, EGCG, and capsaicin inhibit adipocyte differentiation process via activating AMP-activated protein kinase. Biochemical and Biophysical Research Communications 2005; 338: 694-9. https://doi.org/10.1016/j.bbrc.2005.09.195

[24] Lin J, Della-Fera MA, Baile CA. Green tea polyphenol epigallocatechin gallate inhibits adipogenesis and induces apoptosis in 3T3-L1 adipocytes. Obesity Research 2005; 13 : 982-90. https://doi.org/10.1038/oby.2005.115

[25] Kim KJ, Lee MS, Jo K, Hwang JK. Piperidine alkaloids from Piper retrofractum Vahl. protect against high-fat diet-induced obesity by regulating lipid metabolism and activating AMPactivated protein kinase. Biochemical and Biophysical Research Communications 2011; 411(1): 219-25. https://doi.org/10.1016/j.bbrc.2011.06.153

[26] Bastard JP, Maachi M, Lagathu C, Kim MJ, Caron M, Vidal $\mathrm{H}$, Capeau J, Feve B. Recent advances in the relationship between obesity, inflammation, and insulin resistance. European Cytokine Network 2006; 17: 4-12.

[27] Das UN. Is obesity an inflammatory condition? Nutrition 2001; 17: 953-966. https://doi.org/10.1016/S0899-9007(01)00672-4

[28] Fernández-Sánchez $A$, Madrigal-Santillán $E$, Bautista $M$, Esquivel-Soto J. Morales-González Á, Esquivel-Chirino C, Durante-Montiel I, Sánchez-Rivera G, Valadez-Vega C, Morales-González JA. Inflammation, oxidative stress, and obesity. International Journal of Molecular Sciences 2011; 12: 3117-3132.

https://doi.org/10.3390/ijms12053117

[29] Abete I, Goyenechea E, Zulet MA, Martinez JA. Obesity and metabolic syndrome: Potential benefit from specific nutritional components. Nutrition, Metabolism \& Cardiovascular Diseases 2011; 21: B1-B15.

https://doi.org/10.1016/j.numecd.2011.05.001

[30] Hermsdorff HHM, Puchau B, Volp AC, Barbosa KB, Bressan $\mathrm{J}$, Zulet MÁ, Martínez JA. Dietary total antioxidant capacity is inversely related to central adiposity as well as to metabolic and oxidative stress markers in healthy young adults. Nutrition \& Metabolism 2011; 8. https://doi.org/10.1186/1743-7075-8-59 